\title{
Análises histoquímica e morfométrica de lesões endometrióticas induzidas em ratas e tratadas com dexametasona
}

\author{
Histochemical and morphometric analysis of endometriotic lesions induced in female rats and treated with \\ dexamethasone
}

Ana Paula Castor Batista'; Paloma Lys de Medeiros²; Álvaro Aguiar Coelho Teixeira ${ }^{3}$; Valéria Wanderley Teixeira ${ }^{4}$

\section{unitermos} Histoquímica

Morfometria

Endometriose

Ratas Wistar

Dexametasona

\section{resumo}

Introdução: A literatura relata que os implantes endometriais possuem receptores para hormônios esteroides, sendo estimulados principalmente pelo estrógeno, e que algumas estratégicas de tratamento têm sido propostas em modelos experimentais, tais como a utilização de glicocorticoides sintéticos, como a dexametasona. Objetivo: analisar histoquímica e morfometricamente lesões endometrióticas induzidas em ratas e tratadas com $0,8 \mathrm{mg} / \mathrm{kg} / \mathrm{dia}$ de dexametasona. Material e métodos: Quarenta ratas albinas (linhagem Wistar) com 90 dias de vida, pesando aproximadamente $150 \mathrm{~g}$, foram induzidas à endometriose e divididas em grupos: 1. ratas com endometriose e avaliadas após 34 dias (G1); 2 ratas com endometriose e avaliadas após 47 dias (G2); 3. ratas com endometriose e, após 21 dias do pós-operatório, tratadas com dexametasona por 13 dias (G3) e 4. ratas com endometriose e, após 21 dias do pós-operatório, tratadas com dexametasona por 13 dias e eutanasiadas após um período de 13 dias, contados a partir do término do tratamento com dexametasona (G4). Os fragmentos dos implantes endometriais foram fixados em Bouin, incluídos em paraplast e corados por hematoxilina-eosina e tricrômico de Mallory. As médias do número de glândulas foram submetidas ao teste não-paramétrico de Tukey-Kramer $(p \leq 0,05)$. Resultados: A dexametasona reduziu a inflamação nos implantes endometriais, o teor de colágeno no estroma e significativamente a área ocupada pelas glândulas ( $\mathrm{G} 1=123,25 \pm 6,44^{\mathrm{a}} ; \mathrm{G} 2=113 \pm 6,27^{\mathrm{a}} ; \mathrm{G} 3=81,66 \pm$ $3,05^{\mathrm{b}}$; e G4=94 $\pm 6,24^{\mathrm{b}}$ ). Conclusão: A dexametasona, na dosagem utilizada, reduz os efeitos estrogênicos em implantes endometriais em ratas.

\section{abstract}

Introduction: The literature reports that endometrial implants have receptors for steroid hormones primarily stimulated by estrogen and that some treatment strategies have been proposed in experimental models such as the use of synthetic glucocorticoids, for example, dexamethasone. Objective: to analyze histochemically and morphometrically endometriotic lesions induced in rats and treated with dexamethasone $(0.8 \mathrm{mg} / \mathrm{kg} /$ day). Material and Methods: Forty albino female rats (Wistar strain), with 90 days of age, weighing approximately $150 \mathrm{~g}$, were induced with endometriosis and divided into groups: I - rats with endometriosis and evaluated after 34 days, II - rats with endometriosis and evaluated after 47 days, III - rats with endometriosis and 21 days post-surgery treated with dexamethasone for 13 days and IV - rats with endometriosis and 21 days post-surgery treated with dexamethasone for 13 days and euthanized after a period of 13 days starting from the end of treatment. The fragments of endometrial implants were fixed in Bouin, embedded in Paraplast and stained with hematoxylin-eosin and Mallory trichrome. The mean number of glands was compared through nonparametric Tukey-Kramer test $(\mathrm{p} \leq 0,05)$. Results: Dexamethasone reduced inflammation in the endometrial implants, the collagen content in the stroma and decreased significantly the area occupied by glands $\left(\mathrm{GI}-123.25 \pm 6.44^{a} ; \mathrm{IGI}-113 \pm 6.27^{a}\right.$; GIII $-81.66 \pm 3.05^{b}$ and GIV $\left.-94 \pm 6.24^{b}\right)$. Conclusion: The applied dexamethasone dosage reduces estrogenic effects in endometrial implants in rats.

\section{key words}

Histochemistry analysis

Morphometric analysis

Endometriosis

Wistar rats

Dexamethasone.

1. Mestra em Patologia pela Universidade Federal de Pernambuco (UFPE).

2. Doutora em Ciências Biológicas pela UFPE.

3. Doutor em Morfologia pela Universidade Federal de São Paulo (UNIFESP).

4. Doutora em Ciências pela Universidade de São Paulo (USP).

Os experimentos foram realizados no Laboratório de Histologia do Departamento de Morfologia e Fisiologia Animal da UFRPE. 


\section{Introdução}

Estima-se que a endometriose esteja presente em aproximadamente $10 \%$ a $15 \%$ das mulheres em idade fértil e em cerca de $30 \%$ das mulheres com dor pélvica crônica e infertilidade, com aumento desses valores para até 50\% quando esses grupos são avaliados em propedêutica específica desses agravos ${ }^{(1,7,10)}$.

Os mecanismos que levam ao implante do tecido endometrial ectópico permanecem obscuros. Várias hipóteses foram formuladas para explicar a fisiopatologia das lesões, e a mais aceita é a teoria do fluxo retrógrado menstrual quando, durante a menstruação e pelas tubas uterinas, o endométrio atingiria o seu sítio ectópico. Outras hipóteses, como a da disseminação linfática/hematogênica e a da metaplasia celômica, também são aceitas, fazendo parte das várias concepções que tentam explicar a etiopatogenia da endometriose ${ }^{(8)}$. Dmowski et al..$^{(9)}$ sugeriram ainda que a imunidade celular deficiente ou a falta de habilidade do organismo em reconhecer o tecido endometrial ectópico poderiam explicar o desenvolvimento da doença.

Uma das principais razões que limitam os avanços no estudo da endometriose em humanos é a dificuldade de se diagnosticar as lesões, pois é difícil monitorar sua prevalência e progressão sem a utilização de procedimentos invasivos, como a videolaparoscopia. Sendo assim, os modelos animais são extremamente importantes na elucidação dos aspectos da fisiopatologia dessa doença ${ }^{(21)}$. Segundo Rossi et al. ${ }^{(18)}$, o modelo de endometriose em ratas é considerado simples e válido pela maioria dos investigadores.

Durante o ciclo estral de ratas, bem como de outros animais, são observadas fases de atuação do estrógeno (proestro e estro) e da progesterona (metaestro e diestro). Desse modo, vários modelos experimentais de endometriose em ratas (endometriose induzida), que reproduzem histologicamente e endocrinamente essa patologia, têm sido elaborados, proporcionando um melhor entendimento sobre os aspectos fisiológico e bioquímico ${ }^{(7,15)}$.

Embora a endometriose seja parte da prática clínica durante quase um século, as opções terapêuticas incluem desde nenhum tratamento a terapia médica (dietibestrol, andrógenos, contraceptivo oral ou danazol), cirurgia (ressecção e fulguração, cistectomia parcial) ou terapia de combinação. Medicamentos, como acetato de leuprolide, acetato de goserelina e acetato de nafarelina, são todos agentes passíveis de utilização. Terapia cirúrgica é também apropriada, especialmente para fases avançadas da doença ${ }^{(14,23)}$.
Outras técnicas têm sido propostas em modelos experimentais, pois há muitos mecanismos reguladores que mediam ou regulam a ação do estrógeno nos tecidos. Entre esses fatores estão os glicocorticoides sintéticos, como por exemplo a dexametasona ${ }^{(6,16)}$. Os glicocorticoides sintéticos desenvolvidos pela indústria farmacêutica são muito semeIhantes aos naturalmente sintetizados no córtex da glândula adrenal se considerada a sua estrutura química. Porém, a diferença básica deve-se ao fato de que todos os glicocorticoides sintéticos apresentam duas ligações duplas no anel " $A$ " do ciclopentanoperhidrofenantreno, núcleo básico dos hormônios glicocorticoides ${ }^{(16)}$.

Estudos têm demonstrado que a dexametasona inibe o desenvolvimento do processo inflamatório de uma forma geral, e seus efeitos podem também ser observados nas funções reprodutivas, ao bloquear várias respostas induzidas por hormônios estrogênicos no útero de ratas, tais como epitélio hipertrófico, estroma fibroso e glândulas hiperplásicas ${ }^{(6,22)}$.

Análises histológicas de implantes endometriais na parede pélvica de animais experimentais revelaram a presença de glândulas bem desenvolvidas, e que algumas dessas caracterizaram-se por apresentarem a forma cística. Batista et al.(2), administrando dexametasona na dosagem de $0,8 \mathrm{mg} / \mathrm{kg} / \mathrm{dia}$ em ratas, observaram que o processo inflamatório crônico da endometriose não diminuiu após 10 dias de tratamento, enquanto o tratamento por 15 dias consecutivos reverteu o processo inflamatório, embora com persistência de glândulas endometriais. Devemos mencionar ainda que esses autores relataram alta mortalidade nesse último tratamento, além de realizarem as análises logo após o término da administração da dexametasona, sugerindo que há uma tendência de regressão dos implantes com o prolongamento do tratamento. Assim, esse trabalho objetivou avaliar histoquimicamente o estroma dos implantes endometriais, além de quantificar morfometricamente o número de glândulas presentes no processo de reversão da endometriose em ratas tratadas com dexametasona.

\section{Material e métodos}

\section{Manutenção dos animais e formação dos grupos experimentais}

Os experimentos foram realizados no Laboratório de Histologia, do Departamento de Morfologia e Fisiologia Animal da Universidade Federal Rural de Pernambuco (UFRPE). Foram utilizadas 40 ratas albinas (rattus norvegicus albinus) da linhagem Wistar, com 90 dias de idade, pesando 
aproximadamente $150 \mathrm{ng}$, procedentes do biotério do Departamento de Biofísica da UFPE. Esses animais foram mantidos com alimentação e água ad libitum, em local com temperatura de $22^{\circ} \mathrm{C}$ e iluminação artificial com lâmpadas fluorescentes (marca Philips) modelo luz do dia, $40 \mathrm{~W}$, para um fotoperíodo de 12 horas claro e 12 horas escuro, considerando-se o período de luz das 6 às 18 horas.

Após adaptação ao novo ambiente, foram realizados esfregaços vaginais das ratas para a determinação do ciclo estral. As fêmeas que apresentaram três ciclos estrais regulares foram divididas, ao acaso, em quatro grupos, cada um constituído por 10 animais:

- grupo I: ratas com endometriose induzida, sem tratamento e avaliadas após 34 dias (controle I);

- grupo II: ratas com endometriose induzida, sem tratamento e avaliadas após 47 dias (controle II);

- grupo III: ratas com endometriose induzida, tratadas após 21 dias do pós-operatório (PO), com dexametasona por 13 dias e eutanasiadas no dia seguinte ao término do tratamento;

- grupo IV: ratas com endometriose induzida, tratadas após 21 dias do PO, com dexametasona por 13 dias e eutanasiadas depois de 13 dias após o tratamento.

\section{Procedimento cirúrgico para indução da endometriose}

Para a indução da endometriose, foi utilizada a técnica preconizada por Vernon e Wilson ${ }^{(25)}$. Os animais foram anestesiados com sulfato de atropina (Allergan), $1 \mathrm{ml}$ diluído em $1 \mathrm{ml}$ de água destilada, sendo administrado $0,2 \mathrm{ml}$ da solução via intraperitoneal (IP). Em seguida, foi administrado 0,1 ml de xilazina (Rompum ${ }^{\circledast} 20 \mathrm{mg} / \mathrm{ml}$, Bayer S.A.) e 0,1 ml de quetamina (Ketamin ${ }^{\circledast} 50 \mathrm{mg} / \mathrm{ml}$, Cristália) por via intramuscular (IM). Posteriormente, realizou-se a tricotomia da região abdominal. Após esses procedimentos, realizou-se a abertura da cavidade abdominal por incisão longitudinal na linha alba de mais ou menos $2 \mathrm{~cm}$ para a identificação dos cornos uterinos. Uma vez individualizados, foi ressecado aproximadamente $1 \mathrm{~cm}$ do terço médio do corno uterino direito, e realizada a ligadura dos vasos. O segmento uterino retirado foi imediatamente imerso em soro fisiológico, aberto longitudinalmente e, em seguida, fragmentado em dois retângulos medindo aproximadamente de 4 a $5 \mathrm{~mm}$ de arestas. Esses fragmentos foram fixados com fio de sutura de nylon 6.0 na região externa da musculatura da parede anterior da cavidade abdominal, um de cada lado da linha alba, sempre sobre vasos sanguíneos, tomando-se o cuidado para que a porção do endométrio mantivesse o contato com a musculatura. Após esses procedimentos, foi realizada a sutura da cavidade abdominal e, em seguida, da pele.

\section{Tratamento com dexametasona}

Após 21 dias de PO, período necessário para o desenvolvimento dos implantes endometriais e a plena recuperação dos animais do processo cirúrgico ${ }^{(3,25)}$, foi iniciado o tratamento com a dexametasona. O fosfato disódico de dexametasona (Decadron ${ }^{\circledast}$, Aché) foi ultilizado na concentração de $4 \mathrm{mg} / \mathrm{ml}$, sendo administrado por meio de injeções IP na dosagem de $0,8 \mathrm{mg} / \mathrm{kg} / \mathrm{dia}$, durante treze dias, de acordo com metodologia descrita por Batista et al.(2).

\section{Análises histológica e histoquímica}

Ao final dos experimentos, os animais foram eutanasiados. Para tanto, utilizou-se o mesmo procedimento de anestesia para a indução da endometriose. Posteriormente foi realizada uma incisão na pele de aproximadamente 4 $\mathrm{cm}$ para perfeita visualização e retirada dos implantes, que foram clivados longitudinalmente e mergulhados em líquido de Bouin, permanecendo nesse fixador por 48 horas. No procedimento de eutanásia dos animais, foi utilizado o aprofundamento da anestesia.

Os fragmentos foram desidratados em álcool etílico (concentrações crescentes), diafanizados pelo xilol, impregnados e incluídos em paraplast. Posteriormente, os blocos foram cortados em micrótomo do tipo Minot (Leica RM 2035) ajustados para $5 \mu \mathrm{m}$. Os cortes assim obtidos foram colocados em lâminas previamente untadas com albumina de Mayer e mantidos em estufa regulada a $37^{\circ} \mathrm{C}$ durante 24 horas para secagem. Os cortes foram submetidos às técnicas de coloração pela hematoxilina-eosina (HE) e tricrômico de Mallory, sendo posteriormente analisados em microscópio de luz, marca Olympus BX-49, e fotografados em fotomicroscópio Olympus BX-50.

\section{Análise morfométrica}

Para a realização desse procedimento, foi utilizada uma ocular de 10x contendo internamente um retículo de Weibel com 25 pontos $^{(27)}$. Foram utilizadas dez lâminas por grupo pelas quais foram contados quatro campos, todos aleatórios e em sentido horário, levando-se em consideração apenas os pontos que incidiram sobre as glândulas. Esse procedimento foi realizado utilizando a objetiva de 40x e obtendo um aumento final de $400 x$. Foram contados 100 pontos 


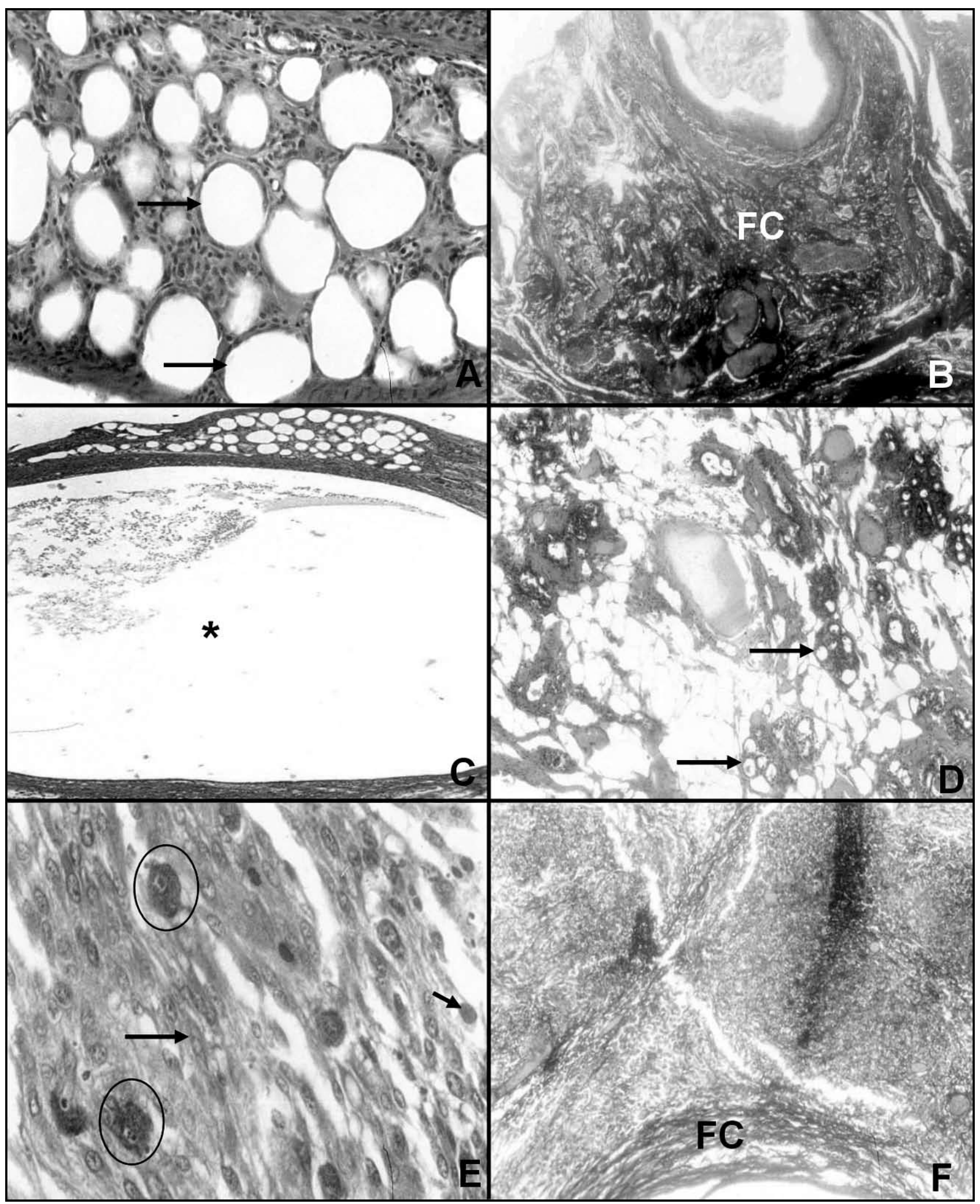

Figura 1 - Fotomicrografias dos implantes endometriais nos grupos experimentais. Grupos l e ll: (A) notar a presença de numerosas glândulas agrupadas (setas), H.E. $\pm 428 x$; (B) glândula formando cisto $\left(^{*}\right)$, H.E. 107x; (C) notar a presença de numerosas fibras colágenas (FC), tricômico de Malory, $\pm 428 x$. Grupos III e IV: (D) glândulas agrupadas em formato de cacho (setas) H.E. $\pm 428 x$; (E) notar macrófagos (círculos), fibroblastos (seta longa), leucócitos (seta curta), H.E. $\pm 428 x$. (F) verificar a presença de poucas $F C$, tricrômico de Malory, $\pm 107 x$ 
por animal (lâmina), totalizando 1.000 pontos por grupo. A observação foi realizada por meio da microscopia de luz da marca Olympus BX-49.

\section{Análise estatística}

A análise do número de glândulas foi realizada mediante teste não-paramétrico de Tukey-Kramer $(p \leq 0,05)$, utilizando o programa estatístico ASSIST (versão 7.3).

\section{Comitê de ética}

O referido estudo foi aprovado pelo Conselho Técnico Administrativo (CTA/UFRPE, $n^{\circ}$. 012872/2006), segundo recomendação ética do Colégio Brasileiro de Experimentação Animal (COBEA) e do National Institute of Health Guide for Care and Use of Laboratory Animals.

\section{Resultados}

\section{Análises histológica e histoquímica}

Nos implantes endometriais dos animais dos grupos I e II foi possível observar que as glândulas apresentaram-se bastante numerosas e agrupadas (Figura 1A). No entanto, algumas glândulas apresentaram acentuada hipertrofia, terminando por formar cistos (Figura 1B).

A análise histoquímica pelo tricrômico de Mallory foi positiva na região de adesão dos implantes com a parede abdominal, demonstrando presença de fibras colágenas, além de um estroma bastante celular (Figura 1C).

Nos grupos II e IV, observou-se também que os implantes endometriais mostraram-se totalmente aderidos à musculatura abdominal (Figura 1D). Notou-se ainda a presença de glândulas agrupadas em forma de cachos e separadas por tecido adiposo, numerosos vasos sanguíneos e um estroma bastante celular com presença de fibroblastos, macrófagos e leucócitos (Figuras 1E).

A reação pelo tricrômico de Mallory também foi positiva, embora menos intensa que nos grupos controles (l e ll), indicando redução no teor de colágeno nos implantes (Figura 1F).

\section{Análise morfométrica das glândulas nos implantes endometriais}

A análise estatística revelou que os implantes endometriais nos animais do grupo III e IV apresentaram redução significativa da área ocupada pelas glândulas quando comparados aos grupos I e ll; no entanto, esses grupos não diferiram entre si (Tabela).

Média das áreas ocupadas pelas glândulas nos implantes endometriais dos diferentes grupos de animais. Os valores numéricos correspondem às médias do número de pontos do retículo que incidiram sobre as Tabela glândulas endometriais

\begin{tabular}{lc}
\hline Grupos & Média* \pm DP $^{\text {I }}$ \\
I & $123,25 \pm 6,44^{\mathrm{a}}$ \\
II & $113 \pm 6,27^{\mathrm{a}}$ \\
III & $81,66 \pm 3,05^{\mathrm{b}}$ \\
IV & $94 \pm 6,24^{\mathrm{b}}$ \\
*Médias seguidas da mesma letra não diferem estatisticamente entre si \\
pelo Tukey-Kramer. \\
DP: desvio padrão.
\end{tabular}

\section{Discussão}

O endométrio normal e os implantes endometriais apresentam receptores para os hormônios esteroides: estrógeno, progesterona e andrógeno. Assim, pode ocorrer uma série de possíveis respostas ao endométrio, destacando-se:

- estados hipoestrogênicos que resultam em atrofia;

- estados hiperandrogênicos que também produzem atrofia;

- doses farmacológicas de progesterona que levam a atrofia endometrial em meio hipoestrogênico ${ }^{(19)}$.

A análise morfológica revelou que os implantes endometriais dos grupos I e II apresentaram-se totalmente aderidos à camada muscular, com grande quantidade de tecido de granulação caracterizado pela infiltração leucocitária e presença de glândulas, adquirindo formato de cistos. Sabese que a presença de tecido de granulação é um indicativo do estabelecimento de um processo inflamatório crônico e, segundo alguns autores, uma inflamação crônica caracteriza-se por dano tecidual persistente, em que os leucócitos polimorfonucleados são escassos ou podem estar ausentes, predominando os mononucleados, como macrófagos e linfócitos ${ }^{(5)}$. A presença de glândulas formando cisto pode estar relacionada com a ação estrogênica, pois Schor et al. ${ }^{(20)}$ relataram a presença de estroma, glândulas e cistos 
em implantes endometriais de ratas ooforectomizadas e tratadas com estrógeno.

Nos grupos tratados com dexametasona, foi evidente a redução do processo inflamatório nos implantes endometriais, sugerindo uma eficiência do tratamento em comparação com os grupos controles. Segundo Bigsby e Cunha ${ }^{(4)}$, a dexametasona bloqueia a atividade mitótica no epitélio uterino por uma ação antagônica com o receptor de estrogênio (ER). Outros autores ainda relatam que o estrógeno é capaz de causar infiltração eosinofílica e edemas no estroma e no miométrio, onde a dexametasona pode agir bloqueando esses efeitos ${ }^{(11,17)}$.

A análise histoquímica dos implantes revelou redução do teor de colágeno nos implantes dos grupos tratados. Esse fato pode estar relacionado com a diminuição da atividade estrogênica pela dexametasona, já que os fibroblastos, responsáveis diretos pela síntese de colágeno, aumentam sua síntese em situações de elevados níveis estrogênicos, sendo, portanto, células estrógeno-dependentes ${ }^{(12,22)}$.

Com relação à presença de glândulas nos implantes endometriais dos grupos tratados, sugere-se que essa condição esteja relacionada com a ação da progesterona. Segundo Wang et al. ${ }^{(26)}$, a aplicação de dexametasona até 12 dias aumentaria significativamente o nível de progesterona e, após dezenove dias de tratamento, ocorreria uma redução desse hormônio. Esse relato não condiz com os nossos resultados, uma vez que a análise estatística realizada revelou que os implantes endometriais nos animais dos grupos tratados com dexametasona (III e IV) apresentaram redução significativa da área ocupada pelas glândulas quando comparados aos controles (I e II). Isso provavelmente pode estar relacionado com a ação da dexametasona no hipotálamo, diminuindo a produção do hormônio gonadotrófico (GnRh) e, consequentemente, a do hormônio luteotrófico $(\mathrm{LH})$, essencial para a ruptura dos folículos ovarianos e formação dos corpos lúteos, resultando em uma diminuição da progesterona ${ }^{(13,24)}$.

\section{Conclusão}

A dexametasona foi capaz de promover redução do processo inflamatório em ratas com endometriose induzida.

A redução do teor de colágeno estromal foi evidente por meio da marcação com o tricrômico de Mallory nos animais tratados com dexametasona.

O tratamento com dexametasona propiciou diminuição das áreas ocupada pelas glândulas nos implantes endometriais.

\section{Referências}

1. BARTKOWIAK, R. et al. Diagnosis and treatment of sigmoidal endometriosis: a case report. Med Sci Monit, v. 6, n. 4, p. 787-90, 2000.

2. BATISTA, A. P. C. et al. Histological evaluation of the induced endometriosis in rats, after treatment with dexamethasone. Int J Morphol, v. 24, n. 4, p. 565-70, 2006.

3. BENJAMINI, E. et al. Imunologia. 4. ed. Rio de Janeiro: Guanabara Koogan, 2002. p. 13-4.

4. BIGSBY, R. M.; CUNHA, G. R. Progesterone and dexamethasone inhibition of uterine epithelial proliferation in models of estrogen - independent growth. Am J Obst Gynecol, v. 158, p. 646-50, 1988.

5. BOUCHER, A. et al. Effect of hormonal agents on monocyte chemotactic protein-1 expression by endometrial epithelial cells of women with endometriosis. Fertil Steril, v. 74 , n. 5 , p. 969-75, 2000.

6. CAMPBELL, P. S. The mechanism of the inhibition of uterotropic responses by acute dexamethasone pretreatment. Endocrinol, v. 103, p. 716-23, 1978.

7. CARVALHO, F. M.; ABRÃO, M. S. Histopatologia da endometriose: a importância da interação entre ginecologista e patologista. In: ABRÃO, M. S. Endometriose: uma visão contemporânea. 1. ed. Rio de Janeiro: Revinter, 2000. p. 35-44.

8. D'HOOGHE, T. M.; HILL, J. A. Endometriose. In: BEREK, J. S. Novak Tratado de Ginecologia. 14. ed. Rio de Janeiro: Guanabara Koogan, 2008. Cap. 29; p. 456-70.

9. DMOWSKI, W. P. et al. Deficient cellular immunity in endometriosis. Am J Ostetet Gynecol, v. 141, p. $377-$ 83, 1981.

10. FOSTER, W. G. et al. Morphologic characteristics of endometriosis in the mouse model: aplication to toxicology. Can J Physiol Pharmacol, v. 75, p. 118896, 1997.

11. MACIEL, S. M. et al. Dexamethasone influences endocrine and ovarian function. Dairy Cattle J Dairy Sci, v. 84, p. 1998-2009, 2001.

12. MEDEIROS, J. P. et al. Ultrastructural analysis of pinealectomy and lack of ligth influence over collagen in the endometrium of rats. Rev Chi Anat, v. 21, n. 3, p. 231-5, 2003. 
13. OGUEH, O. etal. Effect of antenatal dexamethasone therapy on maternal plasma human chorionic gonadotrophin, oestradiol and progesterone. Hum Reprod, v. 14, n. 2, p. 303-6, 1999.

14. OLIVE, D. L.; PRITTS, E. The treatment of endometriosis. A review of the evidence. Ann N Y Acad Sci, v. 955, n. 1, p. 360-72, 2002.

15. PIVA, M. et al. Interleukin-6 differentially stimulates haptoglobin production by peritoneal and endometriotic cells in vitro: a model for endometrial-peritoneal interaction in endometriosis. J Clin Endocrinol Metab, v. 86, n. 6, p. 2553-61, 2001.

16. RHEN, T. et al. Dexamethasone blocks the rapid biological effects of 17 beta-estradiol in the rat uterus without antagonizing its global genomic actions. FASEB J, v. 17, n. 13, p. 1849-70, 2003.

17. RHEN, T.; CIDLOWSKI, J. A. Estrogens and glucocorticoids have opposing effects on the amount and latent activity of complement proteins in the rat uterus. Biol Reprod, v. 74, p. 265-74, 2006.

18. ROSSI, G. et al. Dynamic aspects of endometriosis in a mouse model through analysis of implantation and progression. Arch Gynecol Obstet, v. 263, p. 102-7, 2000.

19. SALTIEL, E.; GARABEDIAN-RUFFALO, S. M. Phamacologic management of endometriosis. Clin Pharm, v. 10, p. 518-30, 1991.
20. SCHOR, E. et al. Effects of conjugated estrogens and progestogen in surgically induced endometriosis in oophorectomized. Clin Exp Obst Gynecol, v. 26, n. 3-4, p. 158-61, 1999.

21. STORY, L.; KENNEDY, S. Animal Studies in Endometriosis: A Review. ILAR Journal, v. 45, n. 2, p. 132-8, 2004.

22. TEIXEIRA, A. A. C. et al. Morphologic aspects of the endometrium, in the estrus phase, of pinealectomized rats. Rev Chi Anat, v. 20, n. 2, p. 145-9, 2002.

23. VALLE, R. F.; SCIARRA, J. J. Endometriosis: Treatment strategies. Ann N Y Acad Sci, v. 997, n. 1, p. 22939, 2003.

24. VAN MERRIS, V. et al. Effects of dexamethasone on mouse ovarian function and pre- implantation embryo development. Reprod Toxicol, v. 23, p. 3241, 2006.

25. VERNON, M. W.; WILSON, E. A. Studies on the surgical induction of endometriosis in the rat. Fertil Steril, v. 44, p. 684-7, 1985.

26. WANG, F. et al. Immunosuppressive levels of glucocorticoid block extrauterine luteolysins in the rat. Biol Reprod, v. 49, p. 66-73, 1993.

27. WEIBEL, E. R. et al. Pratical stereological method for morphometrics cytology. J Cell Biol, v. 30, p. 2338, 1966. 